\title{
A resolução de problemas na educação matemática: onde estamos? E para onde iremos?
}

\author{
Lourdes de la Rosa Onuchic*
}

\section{Resumo}

Neste artigo, é discutida, inicialmente, a complexidade da sala de aula contemporânea. Duas concepções sobre o processo de ensino e aprendizagem de matemática são comparadas, e conceitos de contrato pedagógico, contrato didático, transposição didática, contextualização, resolução de problemas, modelagem, projetos, história da matemática e livro didático são levantados como metodologias que permeiam a sala de aula de matemática, pois o processo de ensino-aprendizagem implica a compreensão de certas relações entre alguém que ensina, alguém que aprende e algo que é objeto de estudo - no caso, o saber matemático. Matemática, educação matemática e resolução de problemas são consideradas no texto, e a metodologia de ensino-aprendizagem-avaliação de matemática através da resolução de problemas é trabalhada num roteiro prescritivo de atividades destinado à orientação dos professores para sua atuação em sala de aula, desenvolvido a partir dessa metodologia criada no Grupo de Trabalho e Estudos em Resolução de Problemas (GTERP).

Palavras-chave: Resolução de problemas. Educação matemática. Matemática. Metodologias de ensino-aprendizagem-avaliação. Sala de aula de matemática.

\section{Introdução}

A programação da IV Jornada Nacional de Educação Matemática e da XVII Jornada Regional de Educação Matemática pautou o tema "A complexidade da sala de aula na contemporaneidade", e, para falar sobre isso, me baseei no Documento do Ministério da Educação e Cultura (MEC) (BRASIL, 2006) intitulado Orientações curriculares para o ensino médio: ciências da natureza, matemática e suas tecnologias. Neste artigo, reproduzo, na íntegra, trechos das páginas 80-86:

Recebido em 12 de outubro de 2012. Aprovado em 10 de janeiro de 2013.

http://dx.doi.org/10.5335/rep.2013.3509

Doutora em Educação Matemática pela USP - São Carlos / SP. Professora e pesquisadora voluntária da Universidade Estadual Paulista Júlio de Mesquita Filho (Unesp), campus de Rio Claro / SP. Coordenadora do Grupo de Trabalho e Estudos em Resolução de Problemas (GTERP). E-mail: Ironuchic@gmail.com 


\section{QUESTÕES DE METODOLOGIA}

Falar de ensino e aprendizagem implica a compreensão de certas relações entre alguém que ensina, alguém que aprende e algo que é o objeto de estudo - no caso, o saber matemático. Nessa tríade, professor-aluno-saber, tem-se presente a subjetividade do professor e dos alunos, que em parte é condicionadora do processo de ensino e aprendizagem.

Para o entendimento da complexidade que permeia uma situação didática, iniciamos falando, de forma resumida, de duas destacadas concepções sobre o processo de ensino e de aprendizagem de Matemática e prosseguimos com a introdução de alguns conceitos, tais como contrato didático, contrato pedagógico, transposição didática, contextualização, que tratam de explicitar alguns dos fenômenos que fazem parte da situação didática.

Sobre o processo de ensino e aprendizagem, uma primeira corrente, historicamente a mais presente nas nossas salas de aula de Matemática, identifica ensino com transmissão de conhecimento, e aprendizagem com mera recepção de conteúdos. Nessa concepção, a aprendizagem é vista como um acúmulo de conhecimentos, e o ensino baseia-se essencialmente na "verbalização" do conhecimento por parte do professor. Se por um lado essa concepção teórica apresenta a vantagem de se atingir um grande número de alunos ao mesmo tempo, visto que a atividade estaria a cargo do professor, por outro lado demanda alunos bastante motivados e atentos à palavra do professor, o que não parece ser o caso para grande parte de nossos alunos, que estão imersos em uma sociedade que oferece uma gama de outras motivações.

Uma segunda corrente, ainda pouco explorada em nossos sistemas de ensino, transfere para o aluno, em grande parte, a responsabilidade pela sua própria aprendizagem, na medida em que o coloca como ator principal desse processo.

As ideias socioconstrutivistas da aprendizagem partem do princípio de que a aprendizagem se realiza pela construção dos conceitos pelo próprio aluno, quando ele é colocado em situação de resolução de problemas. Essa ideia tem como premissa que a aprendizagem se realiza quando o aluno, ao confrontar suas concepções, constrói os conceitos pretendidos pelo professor. Dessa forma, caberia a este o papel de mediador, ou seja, de elemento gerador de situações que propiciem esse confronto de concepções, cabendo ao aluno o papel de construtor de seu próprio conhecimento matemático.

A primeira concepção dá origem ao padrão de ensino "definição exemplos exercícios", ou seja, a introdução de um novo conceito dar-se-ia pela sua apresentação direta, seguida de certo número de exemplos, que serviriam como padrão, e aos quais os alunos iriam se referir em momentos posteriores; a cadeia seria fechada com a apresentação de um grande número de exercícios, bastante conhecidos como "exercícios de fixação".

Já na segunda concepção, tem-se o caminho inverso, ou seja, a aprendizagem de um novo conceito como a última etapa do processo de aprendizagem. Nesse caso, caberia ao aluno a construção do conhecimento matemático que permite resolver o problema, tendo o professor como um mediador e orientador do processo ensino-aprendizagem, responsável pela sistematização do novo conhecimento.

Essas concepções, de certa maneira, estão na base de diferentes metodologias que permeiam a sala de aula de matemática. Uma dessas metodologias é a de contrato didático, que precisa diferenciar-se do contrato pedagógico. 
O contrato pedagógico baseia-se essencialmente na relação professor-aluno, e suas "cláusulas" são, na sua maioria, explicitáveis. No geral, são negociadas entre o professor e os alunos, e se mantêm relativamente estáveis no tempo. É em relação ao terceiro elemento da tríade - o saber matemático - que se tem o conceito de contrato didático. Esse contrato, que representa o "motor" para a aprendizagem de certo conceito matemático, tem suas "cláusulas" bastante implícitas. Elas se tornam explícitas somente quando ocorre o rompimento do contrato por uma das partes (professor ou alunos). [....]. No caso do contrato didático, a ruptura unilateral pode levar à criação de verdadeiros obstáculos à aprendizagem.

Ancorada nas concepções de aprendizagem, e fortemente articulada com o conceito de contrato didático, surge a ideia de transposição didática, que vem frequentemente dividida em dois grandes momentos: a transposição didática externa e a transposição didática interna. A primeira toma como referência as transformações, as inclusões e as exclusões sofridas pelos objetos de conhecimento matemático, desde o momento de sua produção até o momento em que eles chegam à porta das escolas. Atuando, de certa forma, em uma esfera exterior à escola (mas sempre como resposta às suas demandas), o produto dessa transposição didática externa se materializa, em sua maior parte, pelos livros didáticos e pelas orientações curriculares, como o presente documento. A transposição didática interna apresenta-se, por sua própria natureza, no interior da escola e, mais particularmente, em cada uma de nossas salas de aula.

O conceito de transposição didática também aparece intimamente ligado à ideia de contextualização, e ajuda a compreender a dinâmica de produção e circulação dos saberes que chegarão à escola e entrarão em nossas salas de aula. [...]. A contextualização não pode ser feita de maneira ingênua, visto que ela será fundamental para as aprendizagens a serem realizadas - o professor precisa antecipar os conteúdos que são objetos de aprendizagem. Em outras palavras, a contextualização aparece não como uma forma de "ilustrar" o enunciado de um problema, mas como uma maneira de dar sentido ao conhecimento matemático na escola.

A contextualização pode ser feita por meio da resolução de problemas. Vale aqui ressaltar o quanto é importante, para o exercício da cidadania, a competência de analisar um problema e tomar as decisões necessárias à sua resolução. Mas aqui é preciso estar atento aos problemas "fechados", porque esses pouco incentivam o desenvolvimento de habilidades, enquanto que o problema do tipo aberto procura levar o aluno à aquisição de procedimentos para resolução de problemas. A prática em sala de aula desse tipo de problema acaba por transformar a própria relação entre o professor e os alunos e entre os alunos e o conhecimento matemático.

Em anos recentes, os estudos em educação matemática também têm posto em evidência, como um caminho para se trabalhar a Matemática na escola, a ideia de modelagem matemática, que pode ser entendida como a habilidade de transformar problemas da realidade em problemas matemáticos e resolvê-los interpretando suas soluções na linguagem do mundo real. A modelagem matemática, percebida como estratégia de ensino, apresenta fortes conexões com a ideia de resolução de problemas apresentada anteriormente.

Articulada com a ideia de modelagem matemática, tem-se a alternativa de trabalho com projetos. Para desenvolver o trabalho com projetos, o professor deve estabelecer os objetivos educativos e de aprendizagem, selecionar os conteúdos conceituais e procedimentais a serem trabalhados, preestabelecer atividades, provocar reflexões, facilitar recursos, materiais e informações, e analisar o desenvolvimento individual de cada aluno.

A utilização da História da Matemática em sala de aula também pode ser vista como um elemento importante no processo de atribuição de significados aos conceitos matemáticos. É importante, porém, que esse recurso não fique limitado à descrição de fatos ocorridos no passado ou à apresentação de biografias de matemáticos famosos. 
Outra questão importante refere-se à discussão sobre o papel do livro didático nas salas de aula de Matemática. O texto didático traz para a sala de aula mais um personagem, seu autor, que passa a estabelecer um diálogo com o professor e seus alunos, refletindo seus pontos de vista sobre o que é importante ser estudado e sobre a forma mais eficaz de se trabalharem os conceitos matemáticos. O livro didático vem assumindo, há algum tempo, o papel de única referência sobre o saber a ser ensinado, gerando, muitas vezes, a concepção de que "o mais importante no ensino da matemática na escola é trabalhar o livro de capa a capa".

Para abordar a complexidade da sala de aula de matemática, decidi, inicialmente, olhar para a própria matemática. Num artigo de janeiro de 1997, escrito por um professor de matemática da Columbia University/USA, Hyman Bass, intitulado Mathematicians as educators (Matemáticos enquanto educadores), pude ler uma mensagem que é amplamente ouvida hoje e que diz:

As profissões das ciências matemáticas estão numa fase de transição, da qual elas podem emergir menores ou redistribuídas ou até mais dispersas. Sabemos que não somos uma espécie em perigo, mas sabemos que nossa saúde depende de sermos capazes de transcender às nossas tendências históricas para o isolamento, em nosso desejo de ultrapassar a todas as nossas comunidades irmãs ou clientes (1997, p. 18).

Nesse artigo, Bass expõe que a cultura matemática continua sua profunda investigação das estruturas fundamentais de número, espaço, dinâmica, agora com o adicional poder exploratório e processual da nova tecnologia. Essas investigações são guiadas parcialmente por uma evolução puramente intelectual, mas também, basicamente, pelas ciências naturais, às quais a matemática fornece a linguagem e os conceitos adequados para descrição, análise, modelação e simulação. A matemática provê, inclusive, ferramentas para projetos e simulações para a engenharia, a tecnologia e até para a organização dos processos de decisão industriais. Assim, a fase de transição citada por Bass envolve muitas mudanças de foco, indo da importante matemática para aplicações ao trabalho interdisciplinar com as ciências natural e social.

Já a área em que estamos trabalhando - a educação matemática - é relativamente nova e leva a debates intensos professores de matemática de todos os níveis de ensino, educadores matemáticos transitando em um campo de estudos, matemáticos colaborando em currículos, com seus conceitos e conteúdos, suas técnicas operatórias e suas muitas e diferentes aplicações. O que consideramos importante nos processos de ensino e aprendizagem para trabalhar com nossos alunos de um modo eficiente?

A educação matemática está modelada para produzir conhecimento matemático apropriado, com compreensão e habilidades, para diferentes populações de estudantes. A emergência de uma economia mundial altamente competitiva e tecnológica vem, fundamentalmente, ampliando as demandas da educação matemática. 
Essas mesmas mudanças têm feito crescer a necessidade de uma alfabetização matemática para a participação responsável e informada de uma sociedade moderna democrática. E quando a maioria de estudantes fracassa e/ou abandona o estudo dessa disciplina, que é a porta de entrada para a competência e a literacia, isso é julgado como uma deficiência não dos estudantes, mas do sistema educacional.

Chegou, então, a hora de os cientistas matemáticos reconsiderarem seu papel como educadores. De acordo com Bass:

Saber alguma coisa para si mesmo ou para se comunicar com um colega especialista não é a mesma coisa que sabê-la para explicar a um aluno. E diz, ainda, que a Pedagogia, como uma linguagem em si mesma, pode ou liberar ou aprisionar ideias e inspirar ou sufocar o pensamento construtivo (1997, p. 20).

A educação matemática, diferentemente da matemática em si mesma, não é uma ciência exata. Ela é muito mais empírica e inerentemente multidisciplinar. Seus fins não são um fechamento intelectual, mas seu desígnio é ajudar outros seres humanos, com tudo da incerteza e das muitas tentativas que vincula. É uma ciência social, com seus próprios padrões de evidência, métodos de argumentação e construção de teorias, discurso profissional etc. Com uma base de pesquisa estabelecida, da qual grande parte foi aprendida nas poucas décadas passadas, tem uma importante capacidade de desempenho educacional por que os matemáticos acadêmicos são responsáveis.

Referindo-se aos Estados Unidos, Bass relata que matemáticos e educadores matemáticos, na escola básica e nos demais níveis graduados, ao longo da história, têm estado cultural e profissionalmente separados. Há, segundo ele, uma separação visível nas diferentes agendas e culturas, o que se torna claro para qualquer um que contempla a necessidade de melhora na educação matemática, assim como a noção de que esse problema não pode ser realisticamente segmentado. Como cientistas matemáticos, como pesquisadores de educação matemática, como professores universitários e professores do ensino básico, devemos observar nossas pesquisas, na graduação e na pós-graduação, relacionadas ao trabalho de sala de aula, como parte de um empreendimento que nos leve a aprender a nos comunicarmos e a colaborarmos uns com os outros.

No ano 2000, no Yearbook do National Council of Teachers of Mathematics (NCTM), Stephen S. Willoughby, falando em perspectivas sobre educação matemática, advertiu que:

A matemática tem desempenhado um importante papel no desenvolvimento da sociedade desde os tempos pré-históricos até o presente. Que hoje esse papel é mais significativo do que antes e promete tornar-se ainda mais no futuro. Assim, a Educação Matemática é de grande interesse e suscita grandes debates, sendo que muitos dos argumentos e práticas que pedem atenção hoje parecem notadamente semelhantes àqueles do passado (2000, p. 1). 
Willoughby levanta, ainda, as seguintes questões: onde estamos? E para onde iremos? Afirma ele que a quantidade de matemática que se espera dos estudantes tem crescido dramaticamente ao longo do tempo. Citando ideias de filósofos que no decorrer da humanidade influenciaram o ensino e a aprendizagem da matemática, o autor afirma que se chega ao século XX atravessando uma série de reformas e apresenta uma sequência de tendências e perspectivas inovativas sempre almejando o mesmo fim: a aprendizagem da matemática.

Esse autor também se perguntava: por que a educação matemática se mostra tão importante para o século XXI? Qual o papel da tecnologia nesse processo? E termina questionando: para onde iremos? Na tentativa de responder a essa indagação, assim se expressa: embora eu não saiba para onde iremos, tenho fortes opiniões sobre algumas coisas que poderiam ser feitas para melhorar a educação matemática:

- precisa-se ensinar tanto as habilidades básicas quanto as de ordem superior;

- os estudantes deveriam ser levados a acreditar que podem imaginar, representar e compreender a maior parte da matemática trabalhada mesmo se tiverem esquecido um fato ou nunca o tivessem aprendido;

- quando se estivesse usando uma nova tecnologia, o aluno deveria estar seguro de que há uma clara vantagem pedagógica para ela;

- que a educação matemática deveria ser uma atividade para a vida toda e que facilitações para a educação matemática deveriam estar disponíveis;

- que a matemática deveria ser aprendida como um todo integrado, começando com atividades concretas e intuitivas para o aprendiz;

- que todos os estudantes poderiam aprender matemática e que pudessem se mostrar desejosos e capazes de usá-la de modo eficiente;

- que excelentes professores conhecessem diferentes caminhos para ajudar seus alunos a aprender matemática e que, antes de prescreverem-se métodos particulares, se pudesse avaliar seus resultados: conhecimentos de conteúdo, habilidade e desejo de usar apropriadamente a matemática trabalhada (WILLOUGHBY, 2000, p. 1).

O mundo passa por mudanças. A tecnologia está mudando, a matemática está mudando; portanto, a educação matemática, assim como a percepção da sociedade e o apoio concedido a essa disciplina escolar, precisa mudar para ir ao encontro das necessidades do século XXI.

Uma vez que o objetivo da educação matemática é a aprendizagem do aluno, no Brasil onde estamos? Como está nossa educação matemática? O que estamos produzindo? Como a nossa pesquisa acadêmica se relaciona com a nossa educação básica? Há transferência do produto de nossas dissertações e teses para o professor em sala de aula? 


\section{Onde entra, na educação matemática, a resolução de problemas?}

De acordo com Stanic e Kilpatrick (1989), problemas nos currículos remontam pelo menos aos antigos egípcios, chineses e gregos. Os autores citam, como exemplos, o Papiro de Ahmes, copiado pelo escriba homônimo, em 1650 a.C., de um documento ainda mais antigo, um manuscrito matemático egípcio que contém uma coleção de problemas; e um documento chinês de cerca de 1000 a.C. Esses problemas, segundo eles, eram criados por alguém que os apresentava a outros, os quais passavam a conhecê-lo e conseguiam chegar à solução. Séculos se passaram, e problemas com tratamento semelhante são encontrados, inclusive, em livros de matemática dos séculos XIX e XX. O que transparece nesses exemplos, porém, é uma visão muito estreita da aprendizagem da resolução de problemas. Até uma época bastante recente, ensinar resolução de problemas significava apresentar problemas e, talvez, incluir uma técnica de resolução específica. Uma versão mais moderna do desenvolvimento de habilidades nos alunos em resolução de problemas, nos livros-texto, apresenta-se colorida, com desenhos, chamando a atenção para fatos da vida real, mas sempre com alguém resolvendo o problema e deixando-se uma lista com questões semelhantes para serem solucionadas.

Stanick e Kilpatrick (1989) consideram irônico o fato de que, enquanto educadores matemáticos profissionais nas faculdades e nas universidades em seu país começavam a crescer, o lugar da matemática no currículo escolar estava sendo prejudicado. Educadores matemáticos tentavam se ajustar às ideias e aos tempos de mudança, abraçando as opiniões dos críticos, mas o conflito resultante das tradições em disputa levou a uma crise na educação matemática dos anos 1930, uma crise que, em 1989, no entender desses autores, ainda não havia sido resolvida. Por isso, conforme Stanick e Kilpatrick, é especialmente irônico que, em parte, em razão desse ataque ao lugar da matemática no currículo escolar, muitos dos nossos antecessores, embora defendendo os benefícios da matemática para o desenvolvimento humano, não se sentissem à vontade com a ideia de dar aos problemas um papel tão relevante nesse mesmo contexto.

Tais acontecimentos podem ter preparado o terreno para que os educadores matemáticos começassem a pôr ênfase mais específica no desenvolvimento da capacidade de resolver problemas. No entanto, o confronto das ideias básicas sobre a inteligência humana, da educação e do currículo escolar ainda hoje permeia as discussões sobre resolução de problemas.

Stanic e Kilpatrick (1989) observam que, se olharmos para a resolução de problemas nos currículos de matemática nas escolas, desde o antigo Egito até o presente, três diferentes temas gerais a caracterizam: resolução de problemas como 
contexto, resolução de problemas como habilidade e resolução de problemas como arte.

Buscando novas diretrizes e perspectivas para a pesquisa em resolução de problemas no XI International Congress on Mathematical Education (ICME), realizado em 2008 no México, deparamo-nos com o artigo "Future directions and perspective for problem solving research and curriculum development", de autoria de Lyn English, Richard Lesh e Thomas Fennewald. Nesse trabalho, os autores destacam que, desde a década de 1960, numerosos estudos sobre resolução de problemas têm revelado a complexidade do domínio e a dificuldade em transferir descobertas da pesquisa para a prática. Segundo eles, a literatura mostra que o impacto da pesquisa em resolução de problemas no currículo de matemática tem sido limitado, da mesma forma que o acúmulo de conhecimento sobre o ensino de resolução de problemas tem sido lento. Na introdução do artigo, os autores realçam que:

A pesquisa sobre resolução de problemas matemáticos recebeu muita atenção nas últimas décadas. Entre os desenvolvimentos notáveis estão o pioneiro de Polya (1945) sobre como resolver problemas; os estudos de hábeis resolvedores de problemas (por exemplo, Anderson, Boyle \& Reiser, 1985); a pesquisa sobre o ensino de estratégias em resolução de problemas; e heurísticas e posteriores processos metacognitivos (por exemplo, Charles \& Silver, 1988; Lester, Garofalo \& Kroll, 1989); e, mais recentemente, estudos sobre modelação matemática (por exemplo, Lesh \& English, 2007). Presentemente, perspectivas já existentes, há muito tempo, sobre resolução de problemas têm tratado essa pesquisa como um tópico isolado, onde as habilidades em resolução de problemas são assumidas para desenvolver, através da aprendizagem inicial de conceitos e procedimentos seguidos pela prática de "problemas com enunciados", através da exposição a uma série de estratégias (por exemplo, "desenhe um diagrama", "adivinhe e verifique") e, finalmente, através de experiências em aplicar essas competências para resolver problemas "recentes" ou "não rotineiros" (ENGLISH; LESH; FENNEWALD, 2008, p. 1).

Os autores relatam, ainda, que o desenvolvimento de uma teoria importante é, também, muito esperado, acrescentando que:

Nós mostramos como novas perspectivas sobre o desenvolvimento de habilidades em resolução de problemas podem contribuir para o desenvolvimento da teoria, em guiar o projeto de convenientes atividades de aprendizagem. Em particular, exploramos uma perspectiva de modelos e modelação como uma alternativa para as visões existentes sobre resolução de problemas (ENGLISH; LESH; FENNEWALD, 2008, p. 1).

Além disso, English, Lesh e Fennewald enfatizam a urgente necessidade de se levar em consideração a natureza da resolução de problemas em várias áreas do mundo atual, para, então, modernizar nossas perspectivas sobre o ensino e a aprendizagem de resolução de problemas e de conteúdo matemático por meio da resolução de problemas. 
Quando ensinada dessa maneira, a resolução de problemas é vista como independente e isolada do desenvolvimento de ideias, compreensões e processos matemáticos essenciais. Apesar dessas décadas de pesquisa e do desenvolvimento curricular associado, ao que parece, as habilidades em resolução de problemas nos estudantes ainda necessitam de uma melhora substancial, especialmente devido à rápida natureza mutável do mundo contemporâneo (LESTER; KOEHLE, 2003; KUEHNER; MAUCH, 2006; LESH; ZAWOJEWSKI, 2007). O estado atual dessas ocorrências não tem sido ajudado em razão do notável declínio da quantidade de pesquisas em resolução de problemas que foram conduzidas na década passada. Muitos fatores foram identificados como contribuintes para esse declínio, incluindo as tendências cíclicas de desencorajamento na política e nas práticas educacionais, a limitada pesquisa sobre o desenvolvimento de conceitos e de resolução de problemas, o conhecimento insuficiente em resolução de problemas dos estudantes fora da sala de aula, a natureza mutável dos tipos de resolução de problemas, o pensamento matemático necessário para fora da escola e a falta de acúmulo de pesquisa em resolução de problemas (LESH; ZAWOJEWSKI, 2007). Salientam English, Lesh e Fennewald que,

Em Educação Matemática, a pesquisa em resolução de problemas tem focado primeiramente sobre os problemas com enunciado do tipo enfatizado nos livros- texto ou nos testes escolares - onde "problemas" são caracterizados como atividades que envolvem ir dos dados para os objetivos quando o caminho não é óbvio. Com tais situações em mente, o livro How to solve it (1945), de Polya, introduziu a noção de heurísticas - como fazer um desenho, trabalhar de trás para frente, olhar para um problema semelhante, ou identificar os dados e os objetivos (mais tarde referidos, por educadores matemáticos, como estratégias) - cujos pesquisadores, em Educação Matemática, imediatamente reconheceram serem úteis para gerar descrições, feitas depois do ato, dos comportamentos passados por muitos hábeis resolvedores de problemas. Mas, mesmo para resolvedores de problemas menos experientes, essas mesmas heurísticas também eram esperadas para dar respostas úteis para a pergunta: "O que devo fazer quando eu estou impedido de prosseguir?" (2008, p. 2).

Infelizmente, lamentam eles, os últimos cinquenta anos de investigação não deram validação para essas expectativas. No entanto, alguma esperança continua! $\mathrm{E}$ a maioria das pesquisas passadas tem ido em frente para investigar as seguintes questões:

(a) Podem as heurísticas estilo-Polya serem ensinadas?

(b) $\mathrm{O}$ fato de aprender as estratégias (heurísticas) tem provocado impactos positivos sobre as competências dos estudantes?

Quase não existe pesquisa que tenha dado definições operacionais úteis para responder a questões mais fundamentais como:

(a) O que significa "entender" heurísticas tipo-Polya?

(b) Como (e de que maneira) é que essas compreensões se desenvolvem? 
(c) Qual é a natureza dos níveis iniciais de desenvolvimento?

(d) Como o desenvolvimento pode ser observado, documentado e medido (ou avaliado), de forma confiável?

Até que os pesquisadores desenvolvam respostas úteis para essas duas últimas perguntas, não é razoável esperar que um progresso significativo seja feito sobre as duas questões anteriores (ENGLISH; LESH; FENNEWALD, 2008, p. 2).

Apesar da validade da face aparente das heurísticas de Polya, numa revisão da literatura de pesquisa em educação matemática, Begel (1979) conclui que havia pouca evidência para apoiar o apelo de que os processos gerais, que os especialistas usam para descrever seus comportamentos passados em resolução de problemas, também forneceriam prescrições para orientar os passos dos novatos. De forma semelhante, na sua avaliação da literatura sobre resolução de problemas, Silver (1985) evidencia que, mesmo em estudos onde alguma aprendizagem bem-sucedida tenha sido relatada, a transferência de aprendizagem mostra-se inexpressiva.

Conclusões semelhantes são novamente estabelecidas no Handbook for research on mathematics teaching and learning, do NCTM, em Grouws (1992), onde, no capítulo sobre resolução de problemas, Schoenfeld verifica que as tentativas de ensinar os estudantes a usarem as heurísticas e os processos estilo-Polya, em geral, não haviam provado ser bem-sucedidas. No entanto, o autor chegou a sugerir que uma das razões para essa falta de sucesso poderia estar no fato de que muitas das heurísticas de Polya parecem ser descritivas, mas não prescritivas. Schoenfeld sugeriu que a pesquisa e o ensino em resolução de problemas deveriam: ajudar os estudantes a desenvolver um grande número de estratégias mais específicas em resolução de problemas; ensinar estratégias metacognitivas; desenvolver formas de melhorar as crenças dos estudantes sobre a natureza da matemática, a resolução de problemas e suas próprias competências pessoais.

Dez anos depois de as propostas de Schoenfeld terem sido feitas, Lester e Koehle revisaram novamente a literatura e concluíram que a pesquisa em resolução de problemas ainda tinha pouco a oferecer para a prática escolar. Uma explicação para essa falta de sucesso parecia, de uma maneira simples, dizer que a proposta de Schoenfeld elevara a falha básica das heurísticas de Polya para um nível superior. Ou seja, independentemente da atenção focada sobre as heurísticas estilo-Polya ou sobre o modelo dos processos ou crenças metacognitivas estilo-Schoenfeld, listas curtas de processos descritivos ou regras tendiam a ser muito gerais para terem poder prescritivo.

Assim, English, Lesh e Fennewald ressaltam que: 
É hora de reexaminar hipóteses com base sobre o que significa compreender um pequeno número de grandes ideias em matemática elementar. Uma alternativa é a utilização de perspectivas teóricas e acompanhamento de metodologias de pesquisa que nós chamamos de modelo e perspectivas de modelação (MPM) sobre ensino, aprendizagem e resolução de problemas matemáticos (Lesh \& Doerr, 2003) (2008, p. 3).

Nesse artigo, antes de descreverem os aspectos relevantes da MPM, os autores identificam algumas das principais razões que levaram as últimas pesquisas em resolução de problemas produzirem pouco sucesso. Assim, eles abordam sobre os itens: fatores limitantes da pesquisa em resolução de problemas e avançando no campo da pesquisa em resolução de problemas e desenvolvimento curricular.

Eles descrevem cada um dos fatores limitantes da pesquisa em resolução de problemas, que, em seu entender, são: amplitude do pêndulo movido pelos testes; pesquisa limitada sobre desenvolvimento de conceito e resolução de problemas; conhecimento limitado de resolução de problemas nos estudantes além da sala de aula; natureza mutante dos tipos de resolução de problemas e pensamento matemático necessários além da escola; e falta de acúmulo da pesquisa em resolução de problemas.

Como Lester e Koehle alertaram em 2003, há sinais emergentes de que a situação está começando a melhorar. Acreditam que o pêndulo está começando a balançar de volta para a resolução de problemas em nível internacional, dando ímpetos a novas perspectivas sobre a natureza da resolução de problemas e seu papel na matemática escolar.

Ao refocalizarem a atenção sobre resolução de problemas no sentido de que ela pode se tornar um componente integrante do currículo, em vez de ser tratada separadamente como um tópico, muitas vezes até mesmo negligenciado, English, Lesh e Fennewald exploraram as seguintes questões:

- Qual é a natureza da resolução de problemas em várias áreas do mundo de hoje?

- Quais perspectivas orientadas para o futuro são necessárias sobre o ensino e aprendizagem de resolução de problemas, incluindo um foco no desenvolvimento de conceitos matemáticos através da resolução de problemas?

- Como podem os estudos de hábeis resolvedores de problemas contribuir para o desenvolvimento de uma teoria que possa guiar projetos de experiências de aprendizagem que valem a pena?

- Por que modelos e perspectivas de modelação são uma poderosa alternativa para as visões existentes sobre resolução de problemas? $(2008$, p. 6$)$.

Esses autores abordam o item Avançando no campo da pesquisa em resolução de problemas e no desenvolvimento curricular, dando conta de cada um dos subitens desse tópico: a natureza da resolução de problemas do mundo de hoje; perspectivas orientadas para o futuro sobre o ensino e a aprendizagem de resolução de 
problemas; estudos de habilidades em resolução de problemas e suas contribuições para o desenvolvimento de uma teoria; desenvolvimento da teoria: uma perspectiva de modelos e modelação sobre o desenvolvimento de resolução de problemas na escola e além dela. E concluem afirmando que:

A pesquisa sobre resolução de problemas matemáticos estagnou durante grande parte da década de 90 e início deste século. Além disso, a pesquisa que foi conduzida não parece ter se acumulado num corpo substancial de conhecimento, orientado para o futuro, de como se pode efetivamente promover a resolução de problemas dentro e além da sala de aula. Esta falta de progresso é devida principalmente aos muitos anos de elaborações repetidas de concepções governadas por regras de competência em resolução de problemas. Chegou a hora de considerar outras opções para avançar na pesquisa em resolução de problemas e desenvolvimento curricular - "nós temos destacado a necessidade de reexaminar as hipóteses de nível fundamental sobre o que significa compreender conceitos e processos de resolução de problemas matemáticos. Uma poderosa alternativa em que temos avançado é a de utilizar as perspectivas teóricas e as metodologias de pesquisa associadas a uma perspectiva de modelos e modelação (MMP) em ensino, aprendizagem e resolução problemas matemáticos". Adotar uma MMP significa ter pesquisadores que estudam desenvolvimentos de modelos e modelação dos estudantes e que naturalmente utilizam abordagens integradas para explorar o (co)desenvolvimento de conceitos matemáticos, processos de resolução de problemas, funções metacognitivas, disposições, crenças e emoções. Esses pesquisadores também veem processos desenvolvimentais de resolução de problemas, num modo semelhante àquele que fariam ao estudar o desenvolvimento de conceitos matemáticos em áreas temáticas como os números iniciais, a geometria e a álgebra. Além disso, os problemas utilizados são simulações atraentes, situações autênticas de resolução de problemas (por exemplo, a seleção de equipes esportivas para os Jogos Olímpicos) e engajam os alunos no pensar matemático que envolve criar e interpretar situações (descrevendo, explicando, comunicando) pelo menos, tanto quanto ele envolve computar, executar procedimentos e raciocinar dedutivamente (ENGLISH; LESH; FENNEWALD, 2008, p. 10-11).

\section{GTERP e seu trabalho}

O Grupo de Trabalho e Estudos em Resolução de Problemas (GTERP) ${ }^{1}$ tem suas origens no início da década de 1990. No final de 1989, recebi, na State University of San Diego (Susd) na Califórnia (USA), o documento Setting a research agenda - a research agenda for mathematics education, do NCTM. Durante alguns anos, passei vários períodos nessa Universidade, e resolução de problemas passou a ser minha área de trabalho.

Pude entender que, durante a década de 1980, vários recursos em resolução de problemas haviam sido desenvolvidos visando ao trabalho de sala de aula, na forma de coleções de problemas, listas de estratégias, sugestões de atividades e orientações para avaliar o desempenho em resolução de problemas. Muito desse material ajudou os professores a fazerem da resolução de problemas o ponto central de sua atuação. Nessa importante década, também, as dificuldades encon- 
tradas por professores para "ensinar" e por alunos para "aprender" passaram a ser consideradas como objetos de estudo e de reconceitualização por educadores e pesquisadores na educação matemática. Entretanto, havia diferentes linhas de pesquisa por eles defendidas.

Segundo Onuchic e Allevato (2004), ao final da década de 1980, o NCTM, em busca de uma nova reforma para a educação matemática, publicou: Curriculum and evaluation standards for school mathematics, em 1989; Professional standards for teaching mathematics, em 1991; e Assessment standards for school mathematics, em 1995. Esses Standards (padrões) não pretendiam prescrever, passo a passo, como trabalhar esses documentos. Ao contrário, visavam a apresentar objetivos e princípios em defesa de que as práticas curriculares, de ensino e avaliação pudessem ser examinadas. Além disso, tinham como escopo estimular políticos educacionais, pais, professores, administradores, comunidades locais e conselhos escolares a melhorar os programas de matemática em todos os níveis educacionais.

Em 1990, o National Science Foundation (NSF) financiou uma coleção, em larga escala, de projetos de materiais instrucionais para todos os níveis de ensino: elementar, médio e secundário. Surgiu uma nova geração de currículos alinhados com os Standards. Para dar conta dessas novas ideias, foi preciso que um novo enfoque fosse dado às salas de aula e que se uma visão expandida dos algoritmos. Outra característica encontrada nesses currículos é o uso de contextos na resolução de problemas como um meio de desenvolver os conteúdos matemáticos e fazer conexões com outras áreas. Esses currículos retratam a matemática como uma disciplina unificada por tópicos coerentemente integrados.

A partir de 1995, começou, nos Estados Unidos, uma verdadeira "guerra matemática". Houve uma série de críticas à reforma proposta pelos Standards, mas a luta continuou. O NCTM, então, após uma década de aplicação das ideias defendidas nesses documentos, trabalhou sobre críticas e sugestões recebidas e produziu a publicação Principles and standards for school mathematics, a qual foi lançada em abril de 2000, sendo conhecida como os Standards 2000.

Os Standards sugeriram profundas mudanças em quase todos os aspectos do ensino e da aprendizagem de matemática. Os Standards 2000 refinam e elaboram as mensagens dos documentos originais dos Standards, conservando intacta sua visão básica.

No Brasil, apoiados em ideias dos Standards do NCTM, foram criados os Parâmetros Curriculares Nacionais (PCNs):

- PCNs - Matemática - 1ํe e $2^{0}$ ciclos - $1^{\mathrm{a}}$ a $4^{\mathrm{a}}$ séries - 1997;

- PCNs - Matemática - $3^{\circ}$ e $4^{\circ}$ ciclos - $5^{\mathrm{a}}$ a $8^{\mathrm{a}}$ séries - 1998 ;

- PCNs - Matemática - ensino médio - 1999;

- PCNs - Matemática - ensino médio - orientações educacionais complementares aos Parâmetros Curriculares Nacionais: ciências da natureza, matemática e suas tecnologias - 2002; 
Orientações curriculares para o ensino médio: ciências da natureza, matemática e suas tecnologias - 2006 .

Onuchic e Allevato seguem relatando, em seu artigo, que os objetivos gerais da área de matemática, nesses documentos, buscam contemplar várias linhas para trabalhar o ensino desse componente curricular.

Esses objetivos têm como propósito fazer com que os alunos possam pensar matematicamente, levantar ideias matemáticas, estabelecer relações entre elas, saber se comunicar ao falar e escrever sobre elas, desenvolver formas de raciocínio, estabelecer conexões entre temas matemáticos e de fora da matemática, e desenvolver a capacidade de resolver problemas, explorá-los, generalizá-los e até propor novos problemas a partir deles (2004, p. 218).

Como enfrentar as mudanças preconizadas pelos PCNs? Quantos professores estão preparados para utilizar suas recomendações e levar aos seus alunos, em suas salas de aula, um conteúdo que possa se encaixar em determinados padrões de conteúdo, apoiados por padrões de procedimento bem estruturados?

Especificamente, os PCNs indicam a resolução de problemas como ponto de partida das atividades matemáticas e discutem caminhos para se fazer matemática na sala de aula. Nesse contexto, há diferentes caminhos propostos para se chegar a processos de ensino-aprendizagem-avaliação de matemática. Nós, no grupo GTERP, desde os anos 1990, temos trabalhado em resolução de problemas com a "Metodologia de ensino-aprendizagem-avaliação de matemática através da resolução de problemas", onde o ensino e a aprendizagem devem ocorrer, simultaneamente, durante a construção do conhecimento, tendo o professor como guia e os alunos como coconstrutores desse conhecimento. Além disso, essa metodologia integra uma concepção mais atual de avaliação, sendo esta construída em meio à resolução do problema, integrando-se ao ensino com vistas a acompanhar o crescimento dos alunos, aumentando sua aprendizagem e reorientando as práticas em salas de aula quando for necessário.

Corroborando as ideias do GTERP quanto à nossa metodologia, consta, no documento do MEC, Orientações curriculares para o ensino médio, a seguinte citação:

[...] a aprendizagem de um novo conceito matemático dar-se-ia pela apresentação de uma situação-problema ao aluno, ficando a formalização do conceito como a última etapa do processo de aprendizagem. Nesse caso, caberia ao aluno a construção do conhecimento matemático que permite resolver o problema, tendo o professor como um mediador e orientador do processo ensino-aprendizagem, responsável pela sistematização do novo conhecimento (BRASIL, 2006, p. 81).

A maioria de nossos trabalhos, quer dissertações de mestrado (16), quer teses de doutorado (4), faz uso dessa metodologia ao trabalhar diferentes tópicos matemáticos num contexto de sala de aula. Visando ao processo de ensino-aprendizagem-avaliação, apresenta-se a metodologia ao professor numa forma prescritiva, ou seja, professor e alunos juntos desenvolvem esse trabalho, e a aprendizagem 
se realiza de modo coparticipativo e colaborativo em sala de aula. Sete teses de doutoramento estão em andamento no grupo.

No GTERP, faz-se uso de um roteiro de atividades destinado à orientação de professores para a condução de suas aulas:

1) Preparação do problema: selecionar um problema visando à construção de um novo conceito, princípio ou procedimento. Esse problema será chamado problema gerador. É recomendável que o conteúdo matemático necessário para a resolução do problema proposto não tenha ainda sido trabalhado em sala de aula.

2) Leitura individual: entregar uma cópia do problema para cada aluno e solicitar que seja feita sua leitura.

3) Leitura em conjunto: formar grupos e solicitar nova leitura do problema, agora nos grupos:

- se houver dificuldade na leitura do texto, o próprio professor pode auxiliar os alunos, lendo e levando-os a interpretar o problema;

- se houver, no texto do problema, palavras desconhecidas para os alunos, surge um problema secundário. Busca-se uma forma de esclarecer as dúvidas e, se necessário, pode-se, com os alunos, consultar um dicionário.

4) Resolução do problema: de posse do problema, sem dúvidas quanto ao enunciado, os alunos, em seus grupos, num trabalho cooperativo e colaborativo, buscam resolvê-lo. Considerando os alunos como coconstrutores da "matemática nova" que se quer abordar, o problema gerador é aquele que, ao longo de sua resolução, os conduzirá na construção do conteúdo planejado pelo professor para aquela aula.

5) Observar e incentivar: nessa etapa, o professor não tem mais o papel de transmissor do conhecimento. Enquanto buscam resolver o problema, os alunos, em grupos, têm seu comportamento observado, analisado pelo professor, que estimula o trabalho colaborativo, pois, como mediador, leva-os a pensar, dando-lhes tempo para isso, e incentiva a troca de ideias:

- o professor incentiva os alunos a utilizarem seus conhecimentos prévios e técnicas operatórias já conhecidas necessárias à resolução do problema proposto. Estimula-os a escolher diferentes caminhos (métodos) com base nos próprios recursos de que dispõem. Entretanto, é necessário que o professor atenda aos alunos em suas dificuldades, colocando-se como interventor e questionador. De igual modo, a ele cabe acompanhar suas explorações e ajuda-los, quando necessário, a resolver problemas secundários que podem surgir no decurso da resolução: notação, passagem da linguagem vernácula para a linguagem matemática, conceitos relacionados e técnicas operatórias, a fim de possibilitar a continuação do trabalho. 
6) Registro das resoluções na lousa: representantes dos grupos são convidados a registrar, na lousa, suas resoluções. Resoluções certas, erradas ou feitas por diferentes processos devem ser apresentadas para que todos os alunos as analisem e discutam sobre elas.

7) Plenária: para esta etapa, todos os alunos são convidados a discutir as diferentes resoluções registradas na lousa pelos colegas, para defender seus pontos de vista e esclarecer suas dúvidas. O professor coloca-se como guia e mediador das discussões, incentivando a participação ativa e efetiva de todos os alunos. Esse é um momento bastante rico para a aprendizagem.

8) Busca de consenso: após serem sanadas as dúvidas e analisadas as resoluções e soluções obtidas para o problema, o professor incentiva toda a classe a chegar a um consenso sobre o resultado correto.

9) Formalização do conteúdo: neste momento, denominado "formalização", o professor registra na lousa uma apresentação "formal" - organizada e estruturada em linguagem matemática -, padronizando os conceitos, os princípios e os procedimentos construídos por meio da resolução do problema, de modo a destacar as diferentes técnicas operatórias e as demonstrações das propriedades qualificadas sobre o assunto (ONUCHIC; ALLEVATO, 2011, p. 83-85).

Pode-se observar que não é tarefa fácil a de desenvolver o ensino-aprendizagem-avaliação de matemática por meio da resolução de problemas. Tal metodologia demanda professores bem preparados para o seu uso, pois precisam selecionar cuidadosamente os problemas; observar os alunos na busca de soluções para esses problemas, incentivá-los e ouvi-los, mantendo-os confiantes na própria capacidade para resolvê-los. Nas salas de aula onde essa metodologia foi adotada, os alunos se sentiram aptos a dar sentido à matemática que constroem. Professor e alunos, depois dessa experiência, não querem voltar a trabalhar com o método de ensino tradicional.

\section{Solving problems in mathematics education: where have we been? Where shall we go?}

\section{Abstract}

First of all, this article discussed the complexity of the contemporary classroom. Two different conceptions about the teaching and learning process in mathematics are compared, and concepts of pedagogical contract, didactics contract, didactics transposition, contextualization, solving-proble$\mathrm{ms}$, mathematical modeling, projects, history of mathematics and textbooks are raised as methodologies that permeate the mathematical classroom, because the teaching-learning process implies the understanding of certain relationships between someone who teaches, someone who learns 
and something which is the object of study-in case, the mathematical knowledge. Mathematics, Mathematical Education and Solving-Problems are, in the text, considered and the Methodology of Teaching-Learning-Assessment of Mathematics through Problem Solving, in a prescriptive route of activities, for guidance of teachers for their classroom's work is developed from this method, created in GTERP - Working Group.

Keywords: Mathematical education. Mathematics. Methodology of teaching-learning-assessment. Solving-problem.

\section{Referências}

BASS, H. Mathematicians as educators. In: Notices of the AMS, St. Louis, v. 44, n. 1, p. 18-21, 1997.

BRASIL. Ministério da Educação. Parâmetros Curriculares Nacionais: matemática: $1^{\circ}$ e $2^{\circ}$ ciclos. Brasília, DF: MEC, 1997.

Parâmetros Curriculares Nacionais: matemática: 3ํe 4ำ ciclos. Brasília, DF: MEC, 1998.

. Parâmetros Curriculares Nacionais: matemática: ensino médio. Brasília, DF: MEC, 1999.

. Parâmetros Curriculares Nacionais: ensino médio: orientações educacionais complementares aos Parâmetros Curriculares Nacionais: ciências da natureza, matemática e suas tecnologias. Brasília, DF: MEC, 2002.

. Orientações curriculares para o ensino médio. Brasília, DF: MEC, 2006.

ENGLISH, L.; LESH, R.; FENNEWALD, T. Future directions and perspectives for problem solving research and curriculum development. In: CONGRESSO INTERNACIONAL DE EDUCAÇÃO MATEMÁTICA - ICME, 11, Monterrey, México, 2008. Conferência apresentada... Monterrey, México, 2008.

NATIONAL COUNCIL OF TEACHERS OF MATHEMATICS. Curriculum and evaluation standards for teaching mathematics. Reston: NCTM, 1989.

. Professional standards for school mathematics. Reston: NCTM, 1991.

. Assessment standards for school mathematics. Reston: NCTM, 1995.

Principles and standards for school mathematics. Reston: NCTM, 2000.

Special issue: 100 years of mathematics teacher. Reston: NCTM, 2007. v. 100.

ONUCHIC, L. de la R.; ALLEVATO, N. S. G. Novas reflexões sobre o ensino-aprendizagem de matemática através da resolução de problemas. In: BICUDO, M. A. V.; BORBA, M. de C. (Org.). Educação matemática: pesquisa em movimento. São Paulo: Cortez, 2004. p. 212-231.

. Pesquisa em resolução de problemas: caminhos, avanços e novas perspectivas. BOLEMA: Boletim de Educação Matemática, Rio Claro, SP, v. 25, n. 41, p. 73-98, 2011.

STANIC, G. M. A.; KILPATRICK, J. Historical perspectives on problem solving in the mathematics curriculum. In: CHARLES, R. I.; SILVER, E. A. (Ed.). The teaching and assessing of mathematical problem solving. Reston: NCTM, 1989. p. 1-22.

WILLOUGHBY, S. S. Perspectives on mathematics education. In: BURKE, M. J.; FRANCES, R. (Orgs.). Learning mathematics for a new century. Reston, VA: NCTM, 2000. p. 1-15. 